\title{
Development of Hormone-Active Fiber in the Form of Artificial Insulin Depot
}

\author{
A. Medovic Baralic, P. Skundric, Lj. Sretkovic, I. Pajic Lijakovic, M. Kostic \\ Dept. of Textile Engineering, Faculty of Techology and Metallurgy, University of Belgrade, Belgrade, Republic of Serbia \\ Email: adelamed@yahoo.com
}

Received 2012

\begin{abstract}
This study examines the phenomena of the hormone-active fibers obtaining process, in the form of artificial insulin depot. As a fibrous carrier of insulin cation-exchange polyacrylonitrile (PAN) fibers and biodegradable polysaccharide alginate fibers were used. The process of obtaining fibrous artificial insulin depot was based on the chemisorption of insulin from insulin aqueous solutions by these fibers. The parameters of insulin chemisorption reaction were determined and their influence on quantities of bonded insulin in the artificial depot was studied. The impact of fiber polymer nature on the intensity of insulin chemisorption was studied and determined. Also, the location and deposition of insulin in and onto the fiber, fiber topography were studied. The maximum amounts of bounded insulin for the cation-exchange PAN fibers were $395.0 \mathrm{mg}$ porcine insulin chromatographic / $\mathrm{g}$ of fiber, and for the alginate fibers were about $300 \mathrm{mg}$ of porcine insulin chromatographic / $\mathrm{g}$ of fiber.
\end{abstract}

Keywords: Cation-exchange Fibers; Alginate Fibers; Insulin; Chemisorption; Artificial Depot

\section{Introduction}

Insulin release from implantable biologically-active complexes polymer-insulin are the subject of a numerous researchers studies, around the world. Although these systems could be classified into the group of "smart" bio-materials, they are not yet included in clinical practice.

Implantable insulin-polymer systems are designed so that prolonged insulin release directly into the bloodstream thus excluding daily insulin injection into a vein. Previous research in this field yielded promising results in terms of development of highly sensitive polymer - insulin complexes in which insulin release is initiated by a change of the surrounding environment parameters. [1-3]

Fibrous insulin-releasing implants belonging to the new directions of research related to the improvement of diabetes and insulin therapy, and it was subject of this study.

The cation-exchange acrylic (PAN) fibers and alginate fibers are suitable for the chemisorption of insulin in relation with their molecular structure. With their structural characteristics, geometrical form, developed surface, and possibility of chemical modification, these fibers have real potentials to be carriers of large molecules as insulin. For such needs an action-exchange polyacrilonytrile fiber saponified with sodium met silicate has been developed [4-6]. This fiber, besides carboxyl groups also contains smaller number of polar amino and hydroxyl groups, as well as non specified CN- groups. It is characterized by a high $\zeta$ (zeta) potential and it enables establishing of a polyfuncional interaction of sorbet and insulin. Considering the specific properties of nitride groups, ion-exchange PAN fibers, in fact, always has amphoteric properties, so the division of the cation, anion and amphoteric fiber has a conditional character.

Within this work, research has been directed towards obtain- ing of hormone-active polysaccharide fibers as an artificial insulin depot, possessing the possibility of resorption in organism. As fibrous carriers of insulin, alginate fibers have been used. Alginate is highly hydrophilic, biocompatible and biodegradable polysaccharide material. Alginates are linear unbranched polysaccharide polymers containing $\beta$ - (1,4)-linked D-mannuronic acid (M) and $\alpha$ - $(1,4)$-linked L-guluronic acid (G) residues. It is obtained by extraction of brown and red seaweed. Alginates are not random co-polymers but, according to the source algae, consist of blocks of similar and strictly alternating residues (i.e. MMMMMM, GGGGGG, GMGMGM), each of which have different conformational preferences and behavior. [10]

Very broad application of alginate is based on its three main characteristics: good solubility in water and the clotting ability, gelation in the presence of calcium ions (gel forming does not depend on temperature) and the ability to shape the film (Na-alginate and $\mathrm{Ca}$ - alginate films) and fibers. Alginate fibers are typical chemical composition of calcium salts. Given the highly developed surface, the chemical and physical properties and the presence of COO-groups, alginate fibers are very attractive for obtaining controlled release drug depot.

Alginate and PAN fibers characterized by a series of positive structural properties. Requirements concerning of biocompatibility, non-toxity and hydrophility, of both fibers are excellent, so that practically no limit can be used for medical purposes.

The procedure of obtaining artificial insulin depot is based on chemisorption of insulin from water solutions by PAN and alginate fibers.

The chemisorption process comprises the following four stages:

- diffusion of insulin (from the bath) in the direction of the fibrous material,

- adsorption of insulin by the fiber external surface, 
- diffusion of insulin inside the fibrous material and chemical bonding of insulin and fibrous material.

Chemisorption progresses slowly. In practice, one hour or even more is required for the absorption of the insulin from the bath by fibrous. The process beginning by the adsorption of the insulin on the external surface of the fiber and equilibrium is achieved practically in several seconds. The fixation of the insulin on the fiber, by bonding of insulin molecules with macromolecules of the fibrous material, in present case is a momentary process. The chemisorption rate is determined by the speed of insulin diffusion in the pores, both from the solution and from the external surface of the fiber. The speed of insulin diffusion inside the fiber depends on the size of the insulin particles and on the state of the fiber.

The chemisorption process of insulin of ion-exchanged fibers, depends directly on the type and forms of fibrous, static ion-exchange capacity, concentration of insulin solution, $\mathrm{pH}$ value, temperature and duration of the contact between insulin and fiber, bath modulus, etc that have been shown in ours previous experimental research. [6-9]

\section{Materials and Methods}

\subsection{Cation-exchanged PAN fibers}

For this study, cation-exchange polyacrilonitrile fiber, capacity of $1.4 \mathrm{mmol} / \mathrm{g}$ to $1.77 \mathrm{mmol} / \mathrm{g}$, fineness of 6.4 dtex obtained at the Laboratory of Fiber of Faculty of Technology and Metallurgy in Belgrade, were used.

\subsection{Alginate Fibers}

In the present work the bio-degradable polysaccharide alginate fibers, of Russian origin, fineness of 2.5 dtex and the strength of 17-22 cN/dtex, were used.

\subsection{Insulin}

To obtain an artificial depot insulin, porcine insulin, chromatographic insulin, „Novo Nordisk ", Denmark, was used.

\subsection{UV Spectrophotometry}

Insulin chemisorption by cation-exchange PAN and alginate fibers was monitored by UV spectrophotometer. UV spectra were recorded on a spectrophotometer Shimadzu UV-Visible Recording spectrophotometer, UV-260; in the wavelength range $200-400 \mathrm{~nm}$, i.e. in the near UV area.

The sorbed quantity of biologically active preparation was determined by taking UV specters of the solution from which chemisorption has been performed, in previewed intervals of time. In that way the kinetics of chemisorption reaction was also studied. The intensity of the characteristic absorption maximum for insulin decreased in time, this fact pointing out to a decrease of preparation concentration in solution. By reading the absorbency and by using a calibration diagram formed on the bases of spectra belonging to different, in advance defined concentration of insulin, the quantities of preparation bonded to fiber were calculated.

\subsection{Scanning Electron Microscopy (SEM)}

Morphological characteristics of the obtained fiber depot insulin were studied by scanning electron microscopy (JEOL JSM T-20 and JEOL JSM-35). Fiber samples were sputtered by gold under high vacuum.

\section{Result and Discussion}

Kinetics and intensity of insulin chemisorption by ion-change fibers (PAN and alginate) were studied depending on the concentration of insulin solution from which sorption was performed.

Alginate fibers were used in its $\mathrm{H}$-form, cation-exchange PAN fiber in the Na-form. Insulin was sorbed of the buffer solution, concentration of 0.5 and $1.0 \mathrm{~g} / \mathrm{dm}^{3}$. Based on preliminary studies determined the optimal chemisorption condition: $\mathrm{pH} 2.7 \pm 0.1$ (for alginate fibers), $\mathrm{pH} 4.0 \pm 0.1$ (for PAN fibers) and chemisorption temperature $20+2^{\circ} \mathrm{C}$. Chemisorption of insulin was carried out of the liquor ratio 1: 500 (for PAN fibers) 1:100 (for alginate fibers).

Results of fibrous artificial insulin depot obtaining are shown in Table 1 and Table 2.

Experimental results showed that chemisorption flowing freely in both concentrations of insulin solutions, with very high insulin exhaustion from solution. Insulin sorption by cation-exchanged PAN from insulin concentration of $0.5 \mathrm{~g} / \mathrm{dm}^{3}$ was about $80 \%$ and bounded quantity of insulin was 198.9 $\mathrm{mg} / \mathrm{g}$ of fiber. Bounded insulin quantity from insulin concentration of $1.0 \mathrm{~g} / \mathrm{dm}^{3}$ was $396.0 \mathrm{mg} / \mathrm{g}$ of fiber. The maximum amount of insulin bounded by alginate fibers, from the concentration of $0.5 \mathrm{~g} / \mathrm{dm}^{3}$ is $49.9 \mathrm{mg} / \mathrm{g}$ of fiber and from concentration of $1.0 \mathrm{~g} / \mathrm{dm}^{3}$ is $95.3 \mathrm{mg} / \mathrm{g}$ of fiber. It was obvious that the time required to achieve the exhaustion of the insulin solution significantly reduced in chemisorption by alginate fibers. This shown that the multiple insulin sorption by alginate fibers, could get an artificial depots of insulin with a much higher quantity of bounded insulin. Results of the multiple insulin sorption by alginate fibers from concentration of $0.5 \mathrm{~g} / \mathrm{dm}^{3}$ were shown in Table 2.

Table 1. Chemisorption of insulin by ion-exchanged pan fibers and polysaccharide alginate fibers.

\begin{tabular}{ccccc}
\hline $\begin{array}{c}\text { Type of } \\
\text { fibers }\end{array}$ & $\begin{array}{c}\text { Conc. of } \\
\text { insulin } \\
\text { solution, } \\
{\left[\mathrm{g} / \mathrm{dm}^{3}\right]}\end{array}$ & $\begin{array}{c}\text { Time, } \\
{[\mathrm{min}]}\end{array}$ & $\begin{array}{c}\text { Bonded } \\
\text { quantity of } \\
\text { insulin, } Q \\
{[\mathrm{mg} / \mathrm{g}]}\end{array}$ & $\begin{array}{c}\text { Exhausti } \\
\text { on } \\
{[\%]}\end{array}$ \\
\hline $\begin{array}{c}\text { Ion-exchange } \\
\text { PAN fibers }\end{array}$ & 0.5 & 120 & $\mathbf{1 9 8 . 9}$ & 83.6 \\
& 1.0 & 1200 & $\mathbf{3 9 5 . 0}$ & 80,0 \\
Alginate fibers & 0.5 & 60 & $\mathbf{4 9 , 9}$ & 96.9 \\
& 1.0 & 420 & $\mathbf{9 5 . 5}$ & 95.3 \\
\hline
\end{tabular}

Table 2. Multiple chemisorption of insulin by polysaccharide alginate fibers.

\begin{tabular}{ccc}
\hline $\begin{array}{c}\text { Number of immersion in a } \\
\text { fresh solution of insulin }\end{array}$ & $\begin{array}{c}\text { Time, } \\
{[\mathrm{min}]}\end{array}$ & $\begin{array}{c}\text { Bonded quantity of } \\
\text { insulin, Q [mg/g] }\end{array}$ \\
\hline 1 & 60 & 50 \\
2 & 60 & 98 \\
3 & 90 & 142 \\
4 & 120 & 190 \\
5 & 300 & 240 \\
6 & 900 & $\mathbf{2 9 6}$ \\
\hline
\end{tabular}


By multiple sorption reactions quantity of bonded insulin to $300 \mathrm{mg} / \mathrm{g}$ of alginate fiber was achieved.

With information on the molecular weight of alginate and the time required for its bio-degradation in the body, it was possible to calculate in advance the required amount of insulin sorbed in the artificial depot.

Explanations for the different amounts of sorbed insulin by PAN and alginate fibers, lying in the different fibrous nature and their interaction with insulin. These fibers were characterized by a layered structure. Layered structure was especially characteristic of the oriented polymers obtained from any regeneration of natural polymers, in the case of alginate fibers. The presence of small pores and micro vacuoles in the fibers, had a positive impact on increasing the accessibility of active centers and ionic groups for chemisorption process of insulin, as a large protein macromolecules.

Relatively smooth surface and poorly marked structural elements, probably as a result of intense swelling of the fibers during production, characterized topography of alginate fibers. During the insulin chemisorption, most of insulin macromolecules, through the pore system, penetrated the alginate fiber. Topography of gained artificial insulin depots, on base of alginate and PAN fibers, was presented on Figure 1.

Based on electron microscopic images was evident that the topography of the obtained artificial depot was very different. Cation-exchanged fibers, deposited a quantity of insulin on the surface of the fiber, while the alginate fibers on the surface had an insignificant fraction of insulin. The main mass of insulin in both fibers was deposited on the inside, ie by weight of fibers.

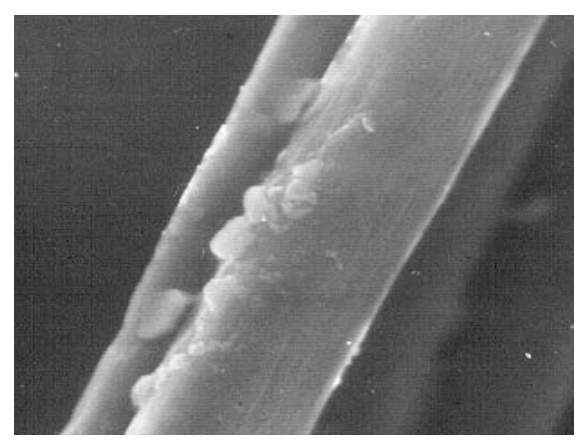

(a)

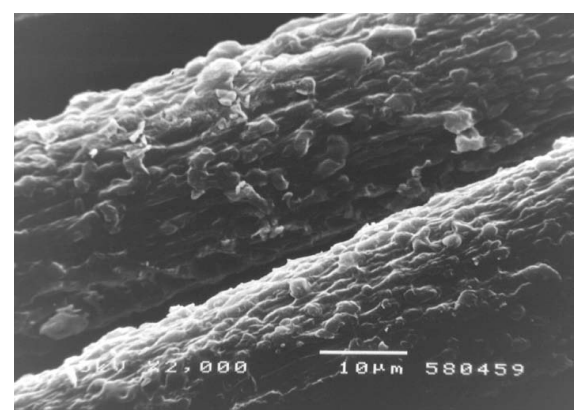

(b)

Figure 1. SEM images-The topography of gained artificial insulin depots obtained by chemisorption reaction of insulin by: (a) biodegradable polysaccharide alginate fibers and (b) PAN fibers.

Given the large amount of sorbed insulin by cation- exchanged PAN fiber, a part of insulin is deposited on the surface of the fiber, as is evident in Figure 1 (b). Structural details on the PAN fiber surface could come form an insulin agglomerates or clusters. The explanation for the difference in topography of obtained artificial depots of insulin could be linked to the different porous structure of fibrous substrate.

\section{Conclusion}

The possibility of obtaining a hormone-active non-biodegradable and biodegradable fibers by insulin chemisorption of PAN and alginate fibers, has been shown. The maximum amounts of bounded insulin of the cation-exchange PAN fibers are $396.0 \mathrm{mg}$ insulin per $\mathrm{g}$ of fiber, and for the alginate fibers are about $300 \mathrm{mg}$ of insulin $\mathrm{g}$ of fiber. The experimental researches showed that the intensity of chemisorption depends in great extent on more parameters: concentration of the insulin, $\mathrm{pH}$ value, temperature, liquor ratio, type of fibrous adsorbent, etc.

Depending on the nature of fibrous matrices, molecular weight and speed of degradation of alginate and sorbed amounts of insulin can be designed artificial depots with the desired amount of insulin and desired service life in the body. Hormone-active PAN fibers are not biodegradable and resorptive, so that on depletion of insulin must be removed from the body.

\section{REFERENCES}

[1] L. Brannon-Peppas, „Polymers in Controlled Drug Delivery, Medical Plastics and Biomaterials Magazine“, November, 1997

[2] G. Coppi, V. Iannuccelli, E. Leo, M.T. Bernabei, R. Cameroni, „Protein immobilization in crosslinked alginate microparticles“, Journal of Microencapsulation, Vol 19(1), pp. 37-44, 2002

[3] R.S. Hermes, R. Narayani, „Polymeric alginate films and alginate beds for the controlled delivery of macromolecules“, Trends. Biomater. Artif. Organs, Vol 5 (2) pp. 54-56, 2002.

[4] L.A. Wolf, Fibres of Specific Properties, Khimiya, Moscow, 1980, in Russian;

[5] P. Skundric, A. Medovic, M. Kostic, „Fibrous systems with programmed biological-activity and their application in medical practice“, Autex Research Journal, Vol.2(2), pp.78-84, 2002

[6] A. Medovic, „Study on phenomenon of fibres with programmed bioactivity production“, Doctoral thesis, 2006, Faculty of Technology and metalurgy, University of Belgrade (in Serbian)

[7] P. Skundric, M. Kostic, A. Medovic, LJ. Spasic-Kljajic, „The Mechanism and Kinetics of Obtaining the Biologically Active Complex Ffiber-Insulin as Artificial Insulin Store“, 3rd AUTEX CONFERENCE, June 26-29, Gdansk, Poland, Book 1, pp. 44 50, 2003

[8] A. Medovic, P. Skundric, M. Kostic, I. Pajic-Lijakovic „Mathematical Modeling of Insulin Sorption by Ion-Exchange Fiber“, Journal of Applied Polymer Science, Volume 104, Issue 1, pp. 253-260, 2007,

[9] A. Medovic, P. Skundric, M. Kostic, I. Pajic-Lijakovic, „The mathematical model of insulin desorption from the bioactive, fibrous artificial store“, Journal of Biomedical Materials Research Part A, Volume 79A, Issue 3, pp. 635 - 642, 2006

[10] J. Fabia, Cz. Slusarczyk, A. Gawlowski, Supermolecular Structure of Alginate Fibers, Fibers\&Textile in Eastern Europe, Vol 13, No 5, pp.53, 2005 